\title{
Removal of ammonia nitrogen from wastewater by three-dimensional electrode system based on solid waste containing iron
}

\author{
Wenyu Yang ${ }^{2^{*}}$, Demin $\mathrm{Li}^{1^{*}}$, Jing Zhang ${ }^{1}$, Zhaoyang Wang ${ }^{{ }^{+}}$ \\ ${ }^{1}$ College of Earth and Environmental Sciences, MOE Key Laboratory of Western China's Environmental Systems, Lanzhou University, Lanzhou \\ 730000, PR China \\ ${ }^{2}$ College of art vocational technology, Lanzhou University of Arts and Science, Lanzhou 730001, PR China \\ "These authors contributed equally to this work.
}

\begin{abstract}
In order to solve the problem of ammonia nitrogen pollution, three-dimensional electrode electrochemical oxidation technology is utilized to transform ammonia nitrogen. The influence of influent $\mathrm{pH}$, power supply and electrolyte concentration on ammonia nitrogen removal by three-dimensional electrode method and its mechanism were discussed by single factor variable analysis. The particle electrode by emission scanning electron microscope (SEM) and energy dispersive spectroscopy (EDS). The results show that the removal efficiency of ammonia nitrogen by three-dimensional electrode is higher than that by two-dimensional electrode. When the aqueous solution is neutral, the direct and indirect oxidation reactions of ammonia nitrogen can reach the best state, and the removal efficiency is the highest. Within a certain range, the electrolytic efficiency will increase with the increase of electrolytic voltage and electrolyte concentration. The reduction of electrode spacing in a certain range can enhance the direct oxidation of ammonia nitrogen and improve the electrolysis efficiency of ammonia nitrogen. Under the conditions of $\mathrm{pH} 7$, power supply voltage $14 \mathrm{~V}$, electrolyte concentration $0.1 \mathrm{~mol} / \mathrm{L}$, electrode spacing $1 \mathrm{~cm}$, electrolytic time 50 min, ammonia nitrogen can be completely removed from the three-dimensional electrode
\end{abstract}

Keywords: Ammonia nitrogen, Iron solid waste, Three-dimensional electrochemical system, Wastewater

\section{Introduction}

With the rapid development of science and technology and economy, the overall scale of heavy and light industries such as petroleum, chemical industry, coking, synthetic ammonia, textile and chemical fertilizer has been gradually expanded. And earlier relaxation of sewage discharge standards, causing more and more highly nitrogen-laden sewage to enter the earth's water, on the earth's water, aquatic animals, human life and other aspects have produced a huge harm and influence [1]. Removing ammonia nitrogen from waste water was an urgent task. Traditional techniques such as blow off, ion exchange, bioanalysis and folding point chlorination method cannot completely remove contaminants and were likely to cause secondary pollution [2]. New pollutant disposal and treat-

This is an Open Access article distributed under the terms of the Creative Commons Attribution Non-Commercial License (http://creativecommons.org/licenses/by-nc/3.0/) which permits unrestricted non-commercial use, distribution, and reproduction in any medium, provided the original work is properly cited.

Copyright (C) 2022 Korean Society of Environmental Engineers ment technologies are emerging rapidly [3]. Advanced electrochemical oxidation can completely remove ammonia nitrogen from the water and little or no secondary pollution and strong controllability [4-7].

Electrochemical oxidation, as a new green technology, has become a research hotspot because of its great advantages. Nowadays, electro-fenton (EF) is becoming an ideal method to remove organic pollutants from wastewater [8]. However, the traditional two-dimensional electrochemical technology has the disadvantages of small effective surface area and low effective current in electrolytic cell $[9,10]$. The emergence of three-dimensional electrochemical technology effectively compensates for these shortcomings. The three dimensional electrolysis method was based on the two dimensional electrolysis method with a particle electrode was added. Particle electrodes accelerate the removal rate of pollutants because they

Received September 01, 2021 Accepted December 20, 2021

${ }^{\dagger}$ Corresponding author

E-mail: wangzhaoyanghit@126.com

Tel: +86-931-8912404 Fax: +86-931-8912404

ORCID: 0000-0003-0678-0346 
can form countless tiny electrodes. By speeding up the transfer of electrons between the pollutant and the anode and cathode, the pollutant becomes other harmless substances [11, 12].

In order to give full play to the advantages of three-dimensional electrochemical technology, it was necessary to consider the performance of particle electrodes and the production cost of particle electrode. At present, the concept of "using waste to treat waste" has attracted much attention in the field of water treatment. In the age of industrial development, all kinds of solid wastes containing iron were abundant. If it can be recycled, it can not only realize the recycling of industrial waste, but also reduce environmental pollution [13, 14]. In this experiment, solid waste containing iron was used as particle electrode, which can solve the problem of the cost of the raw material of the particle electrodes to a certain extent and enable the solid wastes containing iron to be fully reused [15].

At present, three-dimensional electrochemical technology can efficiently remove ammonia nitrogen from wastewater, and its efficient performance has attracted more and more attention. Three-dimensional electrochemistry is considered to be environmentally friendly and one of the most promising technologies for industrialization. However, due to the lack of various factors, the research on the effect of the three-dimensional electrode system on the efficiency and mechanism of ammonia nitrogen removal from wastewater. There is a compromise between efficiency and cost, so it is very important to discuss the influence of these factors on the efficiency of ammonia nitrogen removal by three-dimensional electrolysis.

In this work, the efficiency difference between the three dimensional electrolytic system and the traditional two dimensional electrolytic system is discussed. The removal efficiency and mechanism of ammonia nitrogen from wastewater by three-dimensional electrode system were studied. We use solid wastes containing iron as particle electrodes, the factors such as influent $\mathrm{pH}$, electrolytic voltage, electrolyte concentration and electrodes spacing were changed by single factor variable analysis method to explore the influence of these factors on the efficiency of three-dimensional electrolysis method to remove ammonia nitrogen. The particle electrode was characterized by quantum 200F field emission SEM and EDS. Single factor variable analysis can quickly analyze the influence of this factor on the target. A certain number of parallel experiments were carried out to ensure the accuracy of the results.

\section{Experimental Section}

\subsection{Test Device}

The test device was self-assembled from laboratory materials. The $500 \mathrm{~mL}$ beaker was used as the outer wall of the three-dimensional electrode experiment device. The anode was a graphite rod of $8 \mathrm{~mm}$ in diameter and $15 \mathrm{~mm}$ in length, the diameter of cathode was $6 \mathrm{~mm} \times 80 \mathrm{~mm}, 10 \times 10 \times 1$ stainless steel sheet electrode. The plate area ratio of cathode to anode is 1:1, both are $3.768 \mathrm{~cm}^{2}$. The power supply was a single output DC power supply with controllable voltage. The test device was shown in Fig. 1.

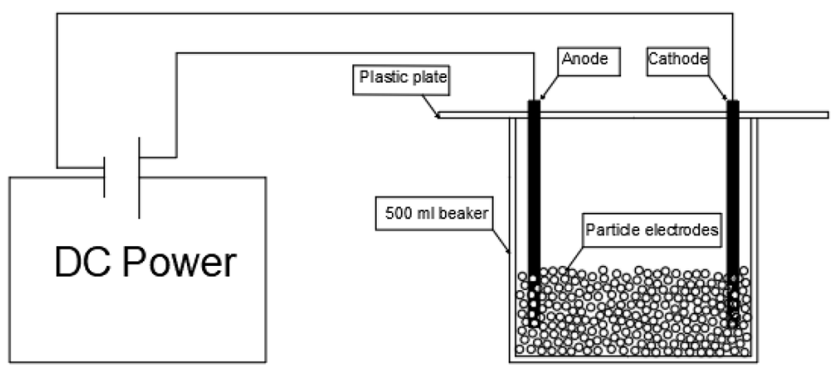

Fig. 1. Schematic of the test device.

\subsection{Preparation of the Particles}

In this work, steel slag was used as principal raw material in particle electrodes preparation. The steel slag was a solid waste produced by laboratory experiments.

The strategy used to obtain particle electrodes was as follow: washed steel slag was milled into powder by a pot mill, and then mixed with clay and pore forming agent. The mixture was then roll into particles with the diameters of $3 \sim 5 \mathrm{~mm}$. The particles was then heated at $1,050^{\circ} \mathrm{C}$ for $30 \mathrm{~min}$ in a tube furnace to obtain particle electrodes.

\subsection{Characterization}

The particle electrode was characterized by quantum $200 \mathrm{~F}$ field emission SEM and EDS.

\subsection{Test Water Samples}

In this work, laboratory configuration of simulated waste water was used as test water samples. All of the chemicals used in this study were analytical grade and used in the experiments without any purification.

The method used to obtain ammonia nitrogen and COD content of simulated waste water was as follows: using the domestic sewage of five different places in lanzhou city, the content of sewage was measured and its average value was obtained. Ammonia nitrogen in the test waste water was prepared by ammonium chloride, the chemical oxygen demand was prepared by glucose. In the end, the concentration of ammonia nitrogen in the obtained waste water was about $20 \mathrm{mg} / \mathrm{L}$, and the concentration of chemical oxygen demand was about $400 \mathrm{mg} / \mathrm{L}$.

\subsection{Comparison of Removal Efficiency of Ammonia Nitrogen by Two-Dimensional Electrode and Three-Dimensional Electrode}

When the initial ammonia concentration was $40 \mathrm{mg} / \mathrm{L}$, influent $\mathrm{pH}$ was 7 , electrolytic voltage was $14 \mathrm{~V}$, electrolyte concentration was $0.1 \mathrm{~mol} / \mathrm{L}$, and electrode spacing was $1 \mathrm{~cm}$. The ammonia nitrogen removal efficiency of two dimensional electrode system and three-dimensional electrode system was compared respectively.

\subsection{Factors Affecting the Removal Efficiency of Ammonia Nitrogen}

\subsection{1. $\mathrm{PH}$ effect}

The fixed electrolytic voltage was $9 \mathrm{~V}$, the electrolyte concentration 
was $0.1 \mathrm{~mol} / \mathrm{L}$, the electrode spacing was $8 \mathrm{~cm}$ and the initial concentration of influent ammonia nitrogen was $20 \mathrm{mg} / \mathrm{L}$. The $\mathrm{pH}$ was adjusted by $\mathrm{NaOH}$ and $\mathrm{H}_{2} \mathrm{SO}_{4}$ solution and make the influent $\mathrm{pH}$ was 3,7 , 11. Electrolysis time was set at $50 \mathrm{~min}$, and water samples were taken every $10 \mathrm{~min}$ and measure the concentration of ammonia nitrogen in the water sample. The influence mechanism of $\mathrm{pH}$ on the removal of ammonia nitrogen by electrolysis method was analyzed.

\subsubsection{Electrolytic voltage}

The fixed $\mathrm{pH}$ was 7 , electrolyte concentration was $0.1 \mathrm{~mol} / \mathrm{L}$, the electrode spacing was $8 \mathrm{~cm}$ and the initial concentration of influent ammonia nitrogen was $20 \mathrm{mg} / \mathrm{L}$. Change the supply voltage, the electrolytic voltages were 9, 11, 13, 14 and 15 V. Electrolysis time was set at $50 \mathrm{~min}$, and water samples were taken every $10 \mathrm{~min}$ and measure the concentration of ammonia nitrogen in the water sample. The influence mechanism of voltage on the removal of ammonia nitrogen by electrolysis method was analyzed.

\subsubsection{Electrolyte concentration}

The fixed $\mathrm{pH}$ was 7 , electrolytic voltage was $14 \mathrm{~V}$ and electrode spacing was $8 \mathrm{~cm}$. The control electrolytes concentration were $0.02,0.05,0.1$ and $0.15 \mathrm{~mol} / \mathrm{L}$. Electrolysis time was set at 50 min, and water samples were taken every $10 \mathrm{~min}$ and measure the concentration of ammonia nitrogen in the water sample. The influence mechanism of electrolyte concentration on the removal of ammonia nitrogen by electrolysis was analyzed.

\subsubsection{Electrodes spacing}

The fixed $\mathrm{pH}$ was 7 , electrolytic voltage was $14 \mathrm{~V}$, electrolyte concentration was $0.1 \mathrm{~mol} / \mathrm{L}$. The control electrode spacing was 8 , 4 , and $1 \mathrm{~cm}$. Electrolysis time was set at $50 \mathrm{~min}$, and water samples were taken every $10 \mathrm{~min}$ and measure the concentration of ammonia nitrogen in the water sample. The influence mechanism of electrode spacing on the removal of ammonia nitrogen by electrolysis was analyzed.

\subsubsection{Initial ammonia concentration}

The fixed $\mathrm{pH}$ was 7 , electrolytic voltage was $14 \mathrm{~V}$, electrolyte concentration was $0.1 \mathrm{~mol} / \mathrm{L}$ and electrode spacing was $1 \mathrm{~cm}$. The initial concentration of ammonia nitrogen was controlled as 21.9, 44.4, 66.2 and $81.2 \mathrm{mg} / \mathrm{L}$. Electrolysis time was set at $50 \mathrm{~min}$, and water samples were taken every $10 \mathrm{~min}$ and measure the concentration of ammonia nitrogen in the water sample. The influence mechanism of the initial concentration of ammonia nitrogen on the removal of ammonia nitrogen by electrolysis was analyzed.

\section{7. $Q A / Q C$ Information}

The above experiments were completed through univariate analysis: factors affecting ammonia nitrogen removal efficiency. In order to ensure the accuracy of the results, we carried out three parallel repeated experiments for each factor and took the average of the results for final analysis and discussion.

\section{Results and Discussion}

\subsection{Characteristic of the Particles}

The surface morphologies of the particle electrodes are exhibited on Fig. 2. High porosity of the particle electrodes can be seen on Fig. 2(a). In addition, several kinds of non-metallic elements: carbon, oxygen and silicon can be observed on the EDS inset Fig. 2(b). The result obtained from EDS further demonstrates the particle electrodes were mainly composed of metals, metallic oxides and silicon oxides.

In view of the special composition of the prepared particle electrode, it is speculated that the particle electrode can effectively promote the electrolysis efficiency in the three-position electrolysis system, and realize the efficient removal of ammonia nitrogen.

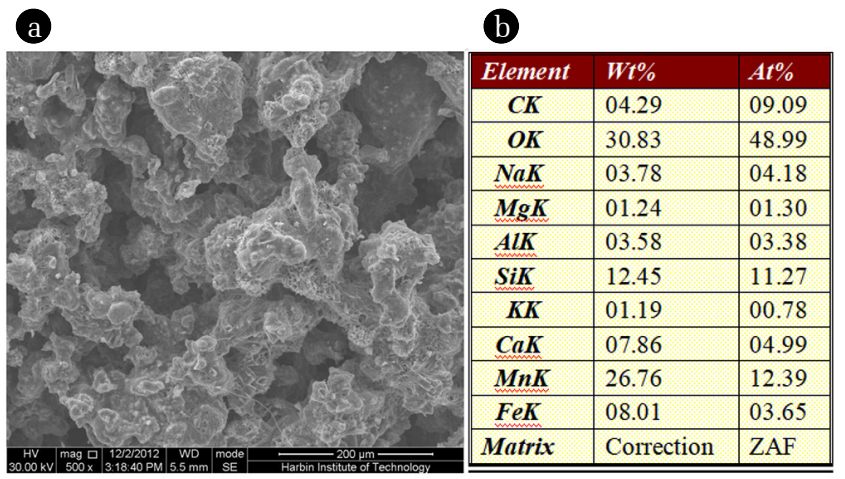

Fig. 2. SEM image of the particle at (a) $200 \mu \mathrm{m}$ and (b) EDS.

\subsection{Comparison of Removal Efficiency of Ammonia Nitrogen by Two-Dimensional Electrode and Three-Dimensional Electrode}

Fig. 3 displays the results obtained by comparing the removal efficiency of ammonia nitrogen with that of two-dimensional electrode and three-dimensional electrode. The removal efficiency of the three dimensional electrode system was much higher than that of the two dimensional electrode system. After electrolysis for 40 $\mathrm{min}$, the removal rate of ammonia nitrogen by three dimensional electrode system had reached $100 \%$. However, the removal rate of ammonia nitrogen by two-dimensional electrolysis system was only $50.26 \%$. It can be seen that the particle electrode as the third electrode can greatly improve the removal of ammonia nitrogen by electrolysis. Finally, the electric current density is calculated through Eq. (1):

$$
\rho=\frac{I}{S} \times 1000
$$

Where, I and S represent the current density (A) and the area of the electrode plate $\left(\mathrm{cm}^{2}\right)$, respectively.

The area $\mathrm{S}$ of the electrode plate is estimated to be $3.768 \mathrm{~cm}^{2}$. The current is $0.63 \mathrm{~A}$ in the three-dimensional electrode system and $0.52 \mathrm{~A}$ in the two-dimensional electrolytic system. According to the formula and measured data, the current density in the three-dimensional electrolytic system is $16.6 \mathrm{~mA} / \mathrm{cm}^{2}$, and that in the two-dimensional electrolytic system is $13.8 \mathrm{~mA} / \mathrm{cm}^{2}$. It can be seen that one of the functions of the particle electrode in the three-dimensional electrode is to improve the mass transfer coefficient of the electrolyte, thus improving the electrolysis efficiency of ammonia nitrogen. 


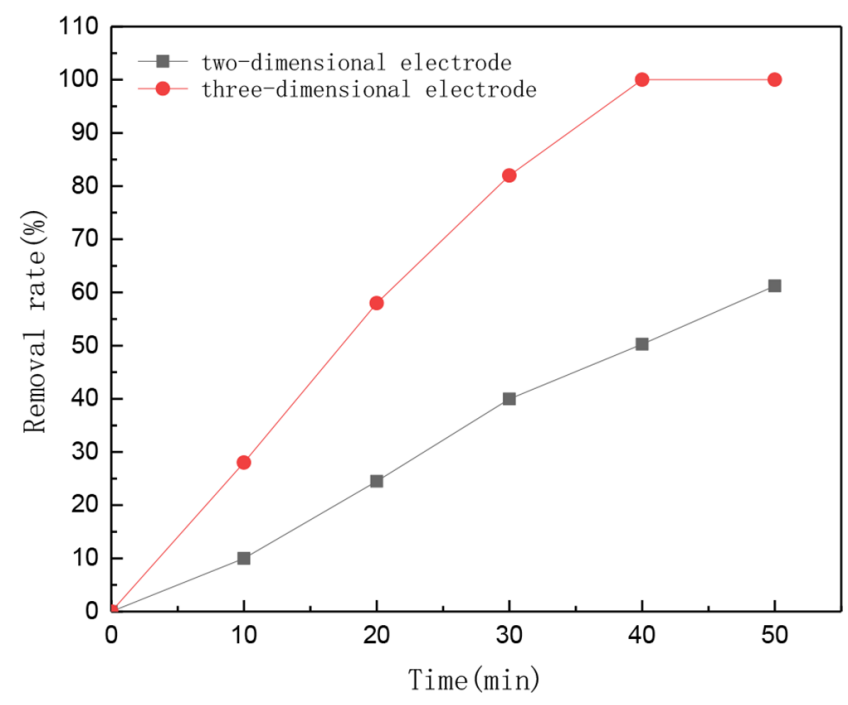

Fig. 3. Comparison of removal efficiency of ammonia nitrogen between two-dimensional electrodes and three-dimensional electrodes.

\subsection{PH Effect}

$\mathrm{PH}$ in water is an important factor affecting the removal efficiency of ammonia nitrogen. $\mathrm{PH}$ affects whether ammonia nitrogen and active chlorine exist in free state or ionic state in water, thus affecting the removal efficiency of ammonia nitrogen. The fixed electrolytic voltage was $9 \mathrm{~V}$, the electrolyte concentration was $0.1 \mathrm{~mol} / \mathrm{L}$, the electrode spacing was $8 \mathrm{~cm}$ and the initial concentration of influent ammonia nitrogen was $20 \mathrm{mg} / \mathrm{L}$. The $\mathrm{pH}$ was adjusted by $\mathrm{NaOH}$ and $\mathrm{H}_{2} \mathrm{SO}_{4}$ solution and make the influent $\mathrm{pH} \mathrm{3,} \mathrm{7,} \mathrm{11.} \mathrm{As} \mathrm{shown} \mathrm{in} \mathrm{Fig.} \mathrm{4,} \mathrm{when} \mathrm{the} \mathrm{influent} \mathrm{pH}$ was 7, the removal rate of ammonia nitrogen reaches the highest value. After $50 \mathrm{~min}$ of electrolysis, the removal rate of ammonia nitrogen can reach $100 \%$. When the solution was acidic and alkaline, the removal rate of ammonia nitrogen is lower. When the $\mathrm{pH}$ of electrolyte was 3 , the removal rate of ammonia nitrogen was $43.89 \%$

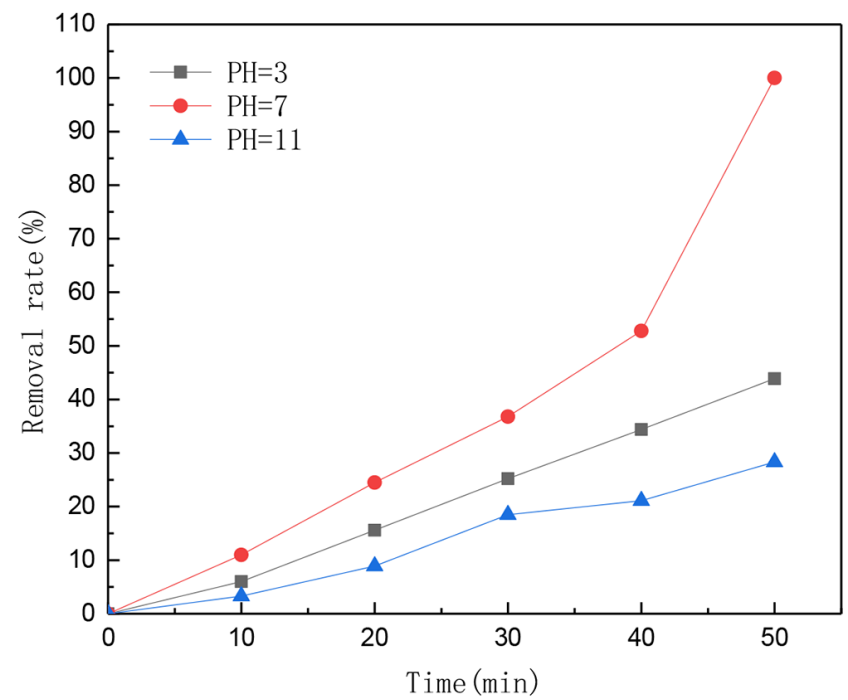

Fig. 4. Effect of influent $\mathrm{pH}$ on removal efficiency of ammonia nitrogen. after electrolysis for $50 \mathrm{~min}$. When the $\mathrm{pH}$ of the electrolyte was 11 , the removal rate of ammonia nitrogen was $28.31 \%$ after electrolysis for $50 \mathrm{~min}$. Consequently, the most suitable $\mathrm{pH}$ value in this reaction system was 7 .

$\mathrm{PH}$ in water affects the presence of $\mathrm{N}$ and $\mathrm{Cl}$ in solution. When the $\mathrm{pH}$ value is low, the nitrogen in the electrolyte mainly exists in the form of ammonium ion $\left(\mathrm{NH}_{4}{ }^{+}\right)$, and the chlorine element in the solution also mainly exists in the form of hypochlorous acid ( $\mathrm{HClO}$ ), so at this time, the indirect oxidation reaction of $\mathrm{NH}_{4}{ }^{+}$and $\mathrm{HClO}$ mainly occurs in the solution. With the increase of $\mathrm{pH}$ value, $\mathrm{NH}_{4}{ }^{+}$is gradually converted to free nitrogen form, $\mathrm{HClO}$ is gradually converted to hypochlorite form (ClO-). In this case, the direct oxidation of ammonia nitrogen on the surface of anode electrode is the main reaction in solution. When the solution is neutral, both indirect and direct oxidation reactions will occur, and the best coordination state can be obtained, and the removal rate of ammonia nitrogen can reach the highest.

\subsection{Electrolytic Voltage}

Electrolytic voltage is also an important factor affecting the removal of ammonia nitrogen by electrolysis. In the experiment, the effective area of the electrode is unchanged, so changing the electrolytic voltage can change the current density of the solution, which can directly affect the removal efficiency of ammonia nitrogen. The fixed $\mathrm{pH}$ was 7 , electrolyte concentration was $0.1 \mathrm{~mol} / \mathrm{L}$, the electrode spacing was $8 \mathrm{~cm}$ and the initial concentration of influent ammonia nitrogen was $20 \mathrm{mg} / \mathrm{L}$. Change the supply voltage, the electrolytic voltages were 9, 11, 13, 14 and $15 \mathrm{~V}$. As shown in Fig. 5(a). The removal efficiency of ammonia nitrogen was increasing gradually from 9 to $15 \mathrm{~V}$ with the increase of electrolytic voltage. However, when the electrolysis voltage was 14 and $15 \mathrm{~V}$ for 50 min, electrolysis efficiency was almost $100 \%$. Increasing the current density in the electrolyte actually speeds up the reaction that already exists in the electrolytic reaction. The electron exchange rate of ammonia nitrogen on anode electrode was improved by increasing current density. In this way, the rate of both indirect and direct oxidation reactions is increased per unit time.

But when the electrolysis voltage exceeds a certain number, the ammonia nitrogen removal efficiency will decrease. This is because when the electrolytic voltage continues to increase, part of the voltage will not go through the electrode reaction but will directly enter the electrolyte, so that the potential difference between the electrolyte and the electrode decreases. The rate of direct and indirect oxidation reaction of ammonia nitrogen slows down, and the electrolytic efficiency of ammonia nitrogen decreases. Increasing the electrolytic voltage will also lead to the increase of the side reaction of hydrogen and oxygen evolution reaction at the anode and cathode poles, so that the effective current of electrolytic ammonia nitrogen is reduced, thus reducing the removal efficiency of ammonia nitrogen. In addition, the large number of bubbles generated in the process of increasing the voltage is not conducive to the adsorption of free ammonia $\left(\mathrm{NH}_{3}\right)$ on the anode surface, thus reducing the direct oxidation reaction of ammonia nitrogen on the electrode.

Therefore, in a certain voltage range, increasing the electrolytic voltage was beneficial to improve the removal efficiency of ammonia 

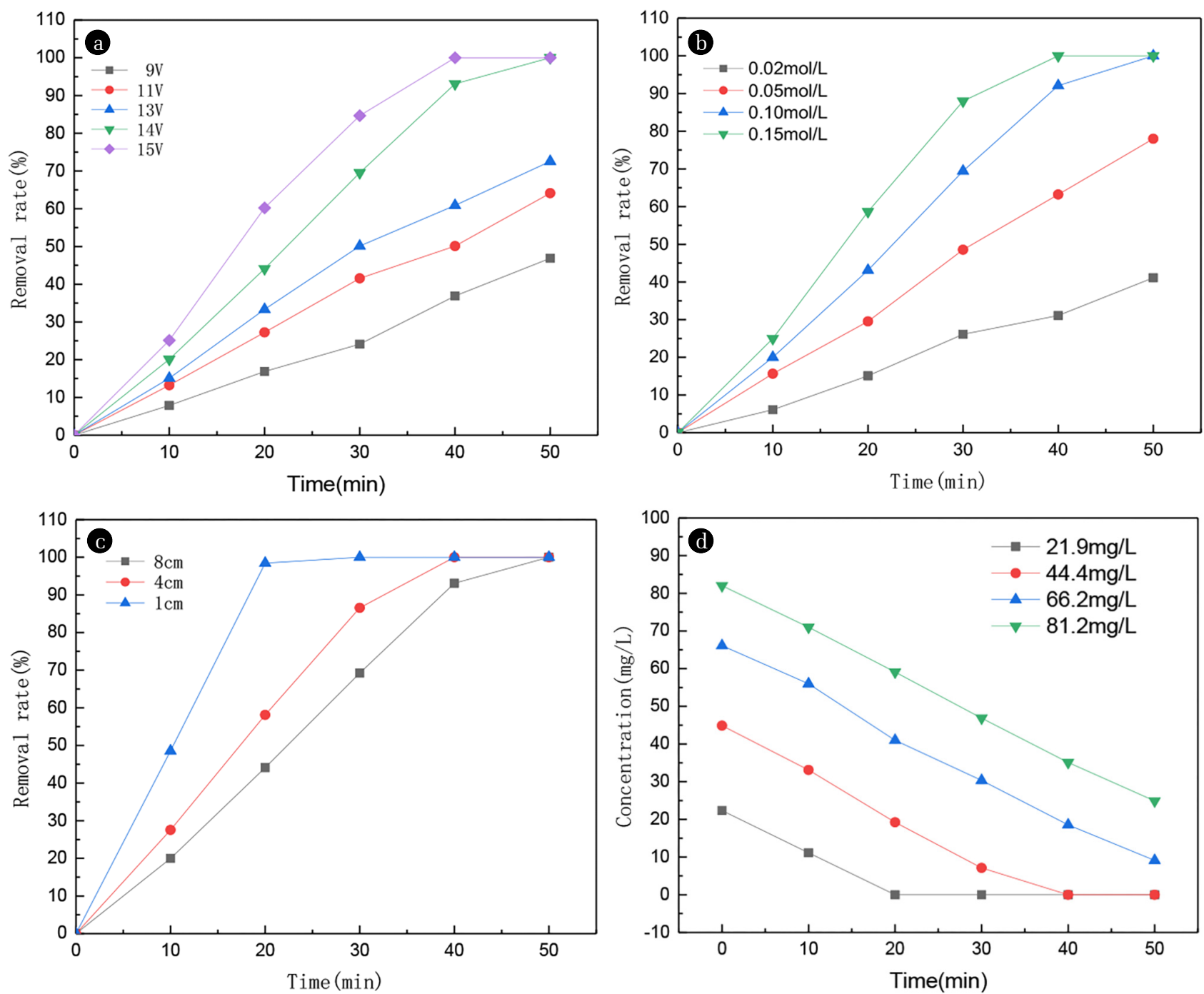

Fig. 5. Effect of different experimental conditions on removal efficiency of ammonia nitrogen.

nitrogen. From an economic perspective, the most suitable electrolytic voltage value in the reaction system is $14 \mathrm{~V}$.

\subsection{Electrolyte Concentration}

The change of electrolyte concentration mainly affects the chloride ion $\left(\mathrm{Cl}^{-}\right)$in the solution. In the electrochemical reaction, the removal efficiency of ammonia nitrogen is mainly affected in two aspects : (1) the precipitation potential of $\mathrm{Cl}^{-}$is smaller than that of hydroxide ion $(\mathrm{OH})$ in the solution, so $\mathrm{Cl}^{-}$will be precipitated earlier than $\mathrm{OH}^{-}$ on the anode electrode to form chlorine gas $\left(\mathrm{Cl}_{2}\right)$. Under the action of the electrode, $\mathrm{Cl}_{2}$ generates active chlorine such as $\mathrm{HClO}$ and $\mathrm{ClO}$, which not only inhibits the production of oxygen $\left(\mathrm{O}_{2}\right)$, but also oxidizes ammonia nitrogen to nitrogen $\left(\mathrm{N}_{2}\right)$ through indirect oxidation, effectively improving the removal efficiency of ammonia nitrogen. (2) Add movable ions to the wastewater to improve the conductivity of the solution, thus reducing the energy consumption of the reaction. Under the same electrolytic voltage condition, the direct electrolytic efficiency of ammonia nitrogen can be improved. In this experiment, the fixed
$\mathrm{pH}$ was 7, electrolytic voltage was $14 \mathrm{~V}$ and electrode spacing was $8 \mathrm{~cm}$. The control electrolytes concentration were $0.02,0.05,0.1$, $0.15 \mathrm{~mol} / \mathrm{L}$. As shown in Fig. 5(b), between 0.02 and $0.15 \mathrm{~mol} / \mathrm{L}$. The removal ability of ammonia nitrogen by electrolytic oxidation method increases with the increase of electrolyte concentration, and when the electrolyte concentration is 0.1 and $0.15 \mathrm{~mol} / \mathrm{L}$ for $50 \mathrm{~min}$, the removal rate of ammonia nitrogen can reach $100 \%$.

However, studies have shown that [16] when the concentration of $\mathrm{Cl}^{-}$and ammonia nitrogen exceeds a certain ratio value, the removal efficiency of ammonia nitrogen will be reduced due to other side reactions caused by active chlorine. At this point, increasing the concentration of $\mathrm{Cl}^{-}$will reduce the removal efficiency of ammonia nitrogen. Therefore, increasing the concentration of $\mathrm{Cl}^{-}$to enhance the removal efficiency of ammonia nitrogen by electrolysis should be controlled within an appropriate range. Considering the economic factors and the possibility that $\mathrm{Cl}^{-}$itself may become a new pollutant, the optimal electrolyte concentration in the reaction system is $0.1 \mathrm{~mol} / \mathrm{L}$. 


\subsection{Electrodes Spacing}

The fixed $\mathrm{pH}$ was 7 , electrolytic voltage was $14 \mathrm{~V}$, electrolyte concentration was $0.1 \mathrm{~mol} / \mathrm{L}$. The control electrode spacing was 8,4 and $1 \mathrm{~cm}$. As shown in Fig. 5(c), the removal efficiency of ammonia nitrogen by electrolytic oxidation method increasing gradually with the electrode spacing decreased from $8 \mathrm{~cm}$ to $1 \mathrm{~cm}$. When electrode spacing was $1 \mathrm{~cm}$, the removal rate of ammonia nitrogen reached $100 \%$ in $30 \mathrm{~min}$, when the electrode spacing was $4 \mathrm{~cm}$, the removal rate of ammonia nitrogen reached $100 \%$ at $40 \mathrm{~min}$. However, when the electrode spacing is $8 \mathrm{~cm}$, it takes $50 \mathrm{~min}$ to completely remove ammonia nitrogen from the waste water. With the decrease of the electrode spacing, the resistance between the two poles decreases, which is conducive to the transmission of current, and the current density increases as the current increases. When the electrolytic spacing is reduced, the diffusion rate of active chlorine and other oxides produced by electrolysis is accelerated, and the contact rate of such oxides with ammonia nitrogen in water is also accelerated, which increases the reaction rate of indirect reaction of ammonia nitrogen. When the distance between anode and cathode is large, the effect of air floatation in electrolysis process is weak, and the adsorption of ammonia nitrogen on anode surface is not strong, which affects the direct oxidation of electrode and leads to the low removal efficiency of ammonia nitrogen. When the distance between the two poles is small, the air floatation between the two poles is obvious, the adsorption of ammonia nitrogen on the anode is strengthened, and the direct reaction of the anode to ammonia nitrogen is strengthened. Therefore, reducing the distance between two poles can not only strengthen the indirect reaction of ammonia nitrogen, but also enhance the direct electron conversion process of ammonia nitrogen.

Some studies have shown that [17] when the electrode spacing is too small, the concentration polarization phenomenon around the electrode is obvious. The electrolyte concentration near the poles is different from the concentration of the solution itself, which makes the potential deviate and affects the electrode reaction rate. At this time, increasing the electrode spacing is beneficial to improve the mixing state of solution and reduce the concentration polarization phenomenon within a certain range of the anode and cathode. Therefore, it is not advisable to reduce the electrode spacing unlimitedly. In conclusion, when the electrode spacing is $1-8 \mathrm{~cm}$, reducing the distance between the anode and cathode poles can greatly improve the removal efficiency of ammonia nitrogen in wastewater. The most suitable electrode spacing in this reaction system is $1 \mathrm{~cm}$.

\subsection{Initial Ammonia Nitrogen Concentration}

The fixed $\mathrm{pH}$ was 7 , electrolytic voltage was $14 \mathrm{~V}$, electrolyte concentration was $0.1 \mathrm{~mol} / \mathrm{L}$ and electrode spacing was $1 \mathrm{~cm}$. The initial concentration of ammonia nitrogen was controlled as 21.9, 44.4, 66.2 and $81.2 \mathrm{mg} / \mathrm{L}$. As shown in Fig. 5(d). Under different initial concentration of ammonia nitrogen, with the change of time, the change rate curve of ammonia nitrogen concentration in water sample is almost parallel. When the initial concentrations were 21.9, 44.4, 66.2 and $81.2 \mathrm{mg} / \mathrm{L}$, the removal rates of ammonia nitrogen were calculated to be $1.10,1.27,1.33 \mathrm{~L}$ and $1.12 \mathrm{mg} / \mathrm{min} \cdot \mathrm{L}$. It can be seen that the initial concentration of ammonia nitrogen has little effect on the electrolytic removal efficiency of ammonia nitrogen. This was consistent with the research conclusion drawn by Li-Li Xu [18]. However, it was different from the conclusion that the removal efficiency of ammonia nitrogen was affected by the initial concentration of ammonia nitrogen obtained from Ding jing [19]. The reason for this is that: in this experiment, the $\mathrm{NH}^{4+} / \mathrm{Cl}^{-}$ ratio was more than 4 , the removal of ammonia nitrogen was mainly controlled by electrochemical reaction. When the ratio was less than 4, the removal of ammonia nitrogen was controlled by both mass transfer and electrochemical reaction. Therefore, in this experiment, the initial concentration of ammonia nitrogen had little effect on the removal of ammonia nitrogen from water by electrolysis.

\subsection{Mechanism of Removal of Ammonia Nitrogen by Three-Dimensional Electrode System}

\subsubsection{Mechanism analysis of removal of ammonia nitrogen by two-dimensional electrode system}

Two-dimensional electrode system can be divided into direct oxidation and indirect oxidation to remove ammonia nitrogen [20, 21]. Direct oxidation is the use of electrochemical action in the solution of the strong oxidation of $\cdot \mathrm{OH}$ radical to degrade organic matter. The electrode reaction formula is:

$$
\begin{aligned}
& \text { Anodic reaction: } 2 \mathrm{H}_{2} \mathrm{O}-2 \mathrm{e} \rightarrow 2 \cdot \mathrm{OH}+2 \mathrm{H}^{+} \\
& \mathrm{C}+\cdot \mathrm{OH} \rightarrow \mathrm{CO}_{2}+\mathrm{H}_{2} \mathrm{O} \\
& 2 \mathrm{NH}_{4}{ }^{+}+6 \cdot \mathrm{OH} \rightarrow \mathrm{N}_{2}+6 \mathrm{H}_{2} \mathrm{O}+2 \mathrm{H}^{+} \\
& 2 \cdot \mathrm{OH} \rightarrow \mathrm{H}_{2} \mathrm{O}+1 / 2 \mathrm{O}_{2} \\
& \text { Cathodic reaction: } 2 \mathrm{H}_{2} \mathrm{O}+2 \mathrm{e} \rightarrow \mathrm{H}_{2}+2 \mathrm{OH}^{-}
\end{aligned}
$$

Indirect oxidation is the direct use of the anion in the wastewater or added, in anodic oxidation to produce strong oxidant, indirectly oxidize the pollutants in the wastewater. For example: sodium chloride $(\mathrm{NaCl})$ was added to the wastewater to adjust the concentration of $\mathrm{Cl}^{-}$, so that it formed $\mathrm{HClO}$ or dissociated to $\mathrm{ClO}^{-}$during anodic oxidation, and participated in the degradation reaction of pollutants. The electrode reaction formula is as follows:

$$
\begin{gathered}
\text { Anodic reaction: } 2 \mathrm{Cl}^{-} \rightarrow \mathrm{Cl}_{2}+2 \mathrm{e} \\
\mathrm{Cl}_{2}+\mathrm{H} \mathrm{O} \rightarrow \mathrm{HClO}+\mathrm{H}^{+}+3 \mathrm{Cl}^{-} \\
2 \mathrm{NH}_{4}^{+}+3 \mathrm{HClO} \rightarrow \mathrm{N}_{2}+3 \mathrm{H}_{2} \mathrm{O}+5 \mathrm{H}^{+}+3 \mathrm{Cl}^{-} \\
2 \mathrm{H}_{2} \mathrm{O} \rightarrow \mathrm{O}_{2}+4 \mathrm{H}^{+}+4 \mathrm{e} \\
\text { Cathodic reaction: } 2 \mathrm{H}_{2} \mathrm{O}+2 \mathrm{e} \rightarrow \mathrm{H}_{2}+2 \mathrm{OH}^{-}
\end{gathered}
$$

\subsubsection{Mechanism analysis of ammonia nitrogen removal by three-dimensional electrode system}

The possible mechanism of the removal of ammonia nitrogen with a three-dimensional electrochemical system was shown in Fig. 6. Three-dimensional electrochemical system processing technology [11] is a new stage by adding granular electrode material between the two poles of Yin and Yang to make the surface charged. Particle electrode greatly increases the direct contact area between electrode 


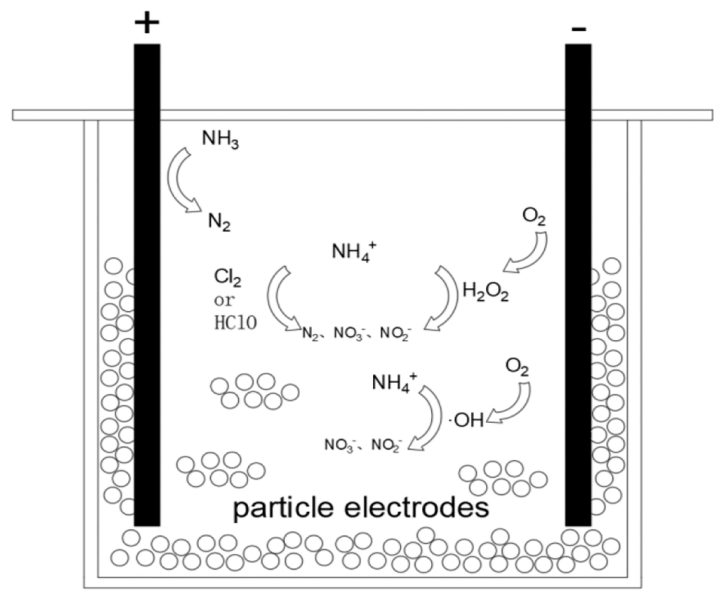

Fig. 6. Mechanism of removal of ammonia nitrogen by three-dimensional electrode system.

and reactant, improves the shortcomings of traditional two-dimensional electrode such as small electrode area and small mass transfer coefficient, and greatly improves the electrolysis efficiency.

The removal of ammonia nitrogen in the three-dimensional electrochemical system is mainly accomplished by two methods. One is direct electrode oxidation. The ammonia nitrogen loses electrons on the anode surface and is decomposed into nitrogen by oxidation [22]. The second was the indirect oxidation of intermediate products, it can be divided into the presence and absence of $\mathrm{Cl}^{-}$, the reaction in the presence of $\mathrm{Cl}^{-}$was the break point chlorination method, the oxidant $\left(\mathrm{Cl}_{2}, \mathrm{HClO}\right)$ reacts with $\mathrm{NH}_{4}{ }^{+}$in a series of oxidation reactions to produce nitrogen. When $\mathrm{Cl}^{-}$was not present, $\cdot \mathrm{OH}$ and other active substances oxidize very small amounts of ammonia nitrogen to nitrite and nitrate nitrogen, but mainly nitrate nitrogen.

Direct oxidation of the anode. Ammonia nitrogen in wastewater includes $\mathrm{NH}_{3}$ and $\mathrm{NH}_{4}{ }^{+}$, which maintain a certain equilibrium state. It is believed that the direct oxidation of ammonia nitrogen on the anode is not obvious when ammonium ion is present in the electrochemical reaction. In the presence of $\mathrm{NH}_{3}$, the anode surface will adsorb $\mathrm{NH}_{3}$ to produce direct oxidation reaction, and finally decompose ammonia nitrogen into $\mathrm{N}_{2}$ [23]. Moran et al. [24] presented the anodic oxidation process of $\mathrm{NH}_{3}$.

$$
\begin{gathered}
\mathrm{NH}_{3} \text { (aq) } \rightarrow \mathrm{NH}_{3} \text { (ads) } \\
\mathrm{NH}_{3} \text { (ads) } \rightarrow \mathrm{NH}_{2} \text { (ads) }+\mathrm{H}^{+}+\mathrm{e}^{-} \\
\mathrm{NH}_{2} \text { (ads) } \rightarrow \mathrm{NH}(\text { ads })+\mathrm{H}^{+}+\mathrm{e}^{-} \\
\mathrm{NH}(\text { ads }) \rightarrow \mathrm{N}(\text { ads })+\mathrm{H}^{+}+\mathrm{e}^{-} \\
\left.\left.\mathrm{NH}_{\mathrm{x}} \text { (ads }\right) \rightarrow \mathrm{NH}_{\mathrm{y}} \text { (ads }\right) \rightarrow \mathrm{N}_{2}+(\mathrm{x}+\mathrm{y}) \mathrm{H}^{+}+(\mathrm{x}+\mathrm{y}) \mathrm{e}^{-}
\end{gathered}
$$

Ci-Co: $\mathrm{x}, \mathrm{y}=1$ or 2; (aq) represents the free state, (ads) Adsorption state.

Indirect oxidation in the presence of $\mathrm{Cl}^{-}$. Ammonia nitrogen can be removed by a series of oxidation reactions between chlorine oxidizer $\left(\mathrm{Cl}_{2}, \mathrm{HClO}, \mathrm{ClO}^{-}\right)$and $\mathrm{NH}_{4}{ }^{+}$to form $\mathrm{N}_{2}$. The presence of
$\mathrm{Cl}^{-}$in the electrolytic reaction can effectively improve the oxidative decomposition of ammonia nitrogen.

$$
\begin{aligned}
& \text { Positive pole: } 2 \mathrm{Cl}^{-} \rightarrow \mathrm{Cl}_{2}+2 \mathrm{e}^{-} \\
& \text {Liquor: } \mathrm{Cl}_{2}+\mathrm{H}_{2} \mathrm{O} \rightarrow \mathrm{HClO}+\mathrm{H}^{+}+\mathrm{Cl}^{-} \\
& \mathrm{HClO}+\mathrm{NH}_{4}^{+} \rightarrow \mathrm{NH}_{2} \mathrm{Cl}+\mathrm{H}_{2} \mathrm{O}+\mathrm{Cl}^{-} \\
& \mathrm{HClO}+\mathrm{NH}_{2} \mathrm{Cl} \rightarrow \mathrm{NHCl}_{2}+\mathrm{H}_{2} \mathrm{O} \\
& \mathrm{NHCl}_{2}+\mathrm{H}_{2} \mathrm{O} \rightarrow \mathrm{NOH}+2 \mathrm{H}^{+}+2 \mathrm{Cl}^{-} \\
& \mathrm{NHCl}_{2}+\mathrm{NOH} \rightarrow \mathrm{N}_{2}+\mathrm{HClO}+\mathrm{H}^{+}+\mathrm{Cl}^{-} \\
& \text {Total reactive: } 2 \mathrm{NH}_{4}{ }^{+}+3 \mathrm{HClO} \rightarrow \\
& \mathrm{N}_{2}+3 \mathrm{H}_{2} \mathrm{O}+5 \mathrm{H}^{+}+3 \mathrm{Cl}^{-}
\end{aligned}
$$

Indirect oxidation of active oxides such as $\cdot \mathrm{OH}$ and $\mathrm{O}_{3} \cdot \cdot \mathrm{OH}$ and $\mathrm{O}_{3}$ generated in the electrolysis process can oxidize a very small amount of ammonia nitrogen to nitric acid nitrogen $\left(\mathrm{NO}_{3}-\mathrm{N}\right)$ and nitrite nitrogen $\left(\mathrm{NO}_{2}-\mathrm{N}\right)$, but the main $\mathrm{NO}_{3}-\mathrm{N}$.

$$
\begin{gathered}
\cdot \mathrm{OH}+\mathrm{NH}_{3} \rightarrow \mathrm{NH}_{2} \mathrm{OH} \rightarrow \mathrm{NHOH} \rightarrow \\
\mathrm{NOH} \rightarrow \mathrm{NO}_{2}^{-} \rightarrow \mathrm{NO}_{3}^{-} \\
\mathrm{O}_{3}+\mathrm{NH}_{3} \rightarrow \mathrm{NO}_{3}^{-} \text {or } \mathrm{NO}_{2}^{-}
\end{gathered}
$$

\section{Conclusions}

In summary, we used solid wastes containing iron as particle electrodes (third electrode). Establishment of three-dimensional electrochemical system. The experimental results show that the removal rate of ammonia nitrogen in three-dimensional electrochemical system with Iron containing waste particles electrodes was significantly higher than that of two-dimensional electrochemical system. There are two main ways to remove ammonia nitrogen by electrochemical method: (1) Direct electrolysis. The ammonia nitrogen in the solution is adsorbed directly on the electrode surface and oxidized to $\mathrm{N}_{2}$. (2) Indirect oxidation method. Indirect oxidation can be divided into two cases with and without $\mathrm{Cl}^{-}$. In the case of $\mathrm{Cl}^{-}$, its essence is the oxidation of ammonia nitrogen by folding point chlorination. Under the action of the electrode, $\mathrm{Cl}^{-}$in the solution generates active chlorine such as $\mathrm{Cl}_{2}$ and $\mathrm{HClO}$ and $\mathrm{ClO}^{-}$ with high oxidation ability, and then generates $\mathrm{N}_{2}$ through the generated active chlorine oxidizes ammonia nitrogen. In the absence of $\mathrm{Cl}^{-}$, the active oxides such as $\mathrm{O}_{3}$ produced in water oxidize ammonia nitrogen to produce $\mathrm{NO}_{3}-\mathrm{N}$ and $\mathrm{NO}_{2}-\mathrm{N}$ and free nitrogen and other products. The factors such as influent $\mathrm{pH}$, electrolytic voltage, electrolyte concentration and electrodes spacing were changed by single factor variable analysis method to explore the influence of these factors on the efficiency of three-dimensional electrolysis method to remove ammonia nitrogen. According to the experimental results, the optimal conditions for removing ammonia nitrogen by the three-dimensional electrode system were as follows: $\mathrm{pH}$ value of solution is 7 , electrolytic voltage was 14 $\mathrm{V}$, electrolyte concentration was $0.1 \mathrm{~mol} / \mathrm{L}$, electrode spacing was 
$1 \mathrm{~cm}$, initial concentration of ammonia concentration was $40 \mathrm{mg} / \mathrm{L}$, and the removal efficiency of ammonia nitrogen can reach nearly $100 \%$ after electrolysis for $50 \mathrm{~min}$.

The removal rate of low concentration ammonia nitrogen by three-dimensional electrolysis can reach almost $100 \%$. However, it cannot get ideal effect when treating high concentration of ammonia nitrogen and complex sewage. At this point, we can consider the combination with other sewage treatment processes, such as biocatalysis, photocatalysis and so on. At present, the research of three-dimensional electrode mainly lies in the selection and analysis of the third electrode particle electrode, so as to improve the removal efficiency of three-dimensional electrolysis. Therefore, we can further study the mechanism of pollutant removal by three-dimensional electrolysis, and obtain the best electrolysis effect by changing some reaction parameters.

\section{Acknowledgments}

This work is partially supported by the Natural Science Foundation of China (Grant no. 21906011), the Postdoctoral Science Foundation of China (Grant no. 2018M643412), and the Open Foundation of MOE Key Laboratory of Western China's Environmental System, Lanzhou University and the Fundamental Research Funds for the Central Universities (lzujbky-2021-kb01).

\section{Author Contributions}

W.Y. (Lecturer) and D.L. (Master Student) did writing-original draft preparation. J.Z. (Undergraduate) did writing-review and editing. Z.W. (Associate Professor) did writing-review and editing, supervision, project administration and funding acquisition.

\section{References}

1. Tao MX, Chen M, Hu LW, Li FG, Shi YL, Yang Q. Research progress of biotechnology in the treatment of ammonia-nitrogen waste water. J. Mod. Chem. Ind. 2018;38(12):24-28.

2. Xu XR, Li XZ. Degradation of azo dye Orange G in aqueous solutions by persulfate with ferrous ion. Sep. Purif. Technol. 2010;72(1):105-111.

3. Khan NA, Khan SU, Ahmed S, et al. Recent trends in disposal and treatment technologies of emerging-pollutants-A critical review. Trac-Trends Anal. Chem. 2020;122:115-744.

4. Khan AH, Khan NA, Ahmed S, et al. Application of advanced oxidation processes followed by different treatment technologies for hospital wastewater treatment. J. Clean. Prod. 2020;269:122-411.

5. Feng YJ, Li XY, You H, et al. Application of electrochemical technology in environmental engineering. Beijing: Chem. Ind. Press; 2002.

6. Marinčić L, Leitz FB. Electro-oxidation of ammonia in waste water. J. Appl. Electrochem. 1978;8(4):333-345.

7. Zhong C, Hu WB, Cheng YF. Recent advances in electrocatalysts for electro-oxidation of ammonia. J. Mater. Chem. A. 2013;1(10): 3216-3238.

8. Zakeri HR, Yousefi M, Mohammadi AA, et al. Chemical coagulation-electro fenton as a superior combination process for treatment of dairy wastewater: performance and modelling. Int. J. Environ. Sci. Technol. 2021:1-14.

9. Somensi CA, Simionatto EL, Bertoli SL, et al. Use of ozone in a pilot-scale plant for textile waste water pre-treatment: Physico-chemical efficiency, degradation by-products identification and environmental toxicity of treated waste water. $J$. Hazard. Mater. 2010;175(1-3):235-240.

10. Zhang J, Ma C, Sun Y, et al. Hydroxyl radical reactions with 2-chlorophenol as a model for oxidation in supercritical water. Res. Chem. Intermed. 2014;40(3):973-990.

11. Su J, Liu J, Zhu BB, et al. Three-dimensional electrode technology and its application in environmental pollution control J. Chem. Technol. Dev. 2013;42(2):22-27.

12. Qu JH, Liu HJ. Electrochemical principles and techniques for water treatment. Beijing: sci. Press; 2007.

13. Yue X, Li XM, Wang DB, et al. Simultaneous phosphate and COD cr removals for landfill leachate using modified honeycomb cinders as an adsorbent. J. Hazard. Mater. 2011;190(1):553-558.

14. Zhu J, Baig SA, Sheng T, et al. $\mathrm{Fe}_{3} \mathrm{O}_{4}$ and $\mathrm{MnO}_{2}$ assembled on honeycomb briquette cinders (HBC) for arsenic removal from aqueous solutions. J. Hazard. Mater. 2015;286:220-8.

15. Liu S, Wang Z, Li J, et al. Fabrication of slag particle three-dimensional electrode system for methylene blue degradation: Characterization, performance and mechanism study. Chemosphere 2018;213:377-383.

16. Vanlangendonck Y, Corbisier D, Lierde AV. Influence of operating conditionson the ammonia electro-oxidation rate in wastewaters from power plants. Water Res. 2005;39(13):3028-3034.

17. Daneshvar N, Sorkhabi HA, Kasiri MB. Decolorization of dye solution containing Acid Red 14 by electrocoagulation with a comparative investigation of different electrode connections. J. Hazard. Mater. 2004;112(1-2):55-62.

18. Xu LL, Shi HC, Chen JL. Ti/ $\mathrm{RuO}_{2}-\mathrm{TiO}_{2}-\mathrm{IRO}_{2}-\mathrm{SnO}_{2}$ electrode electrolytic oxidation of ammonia-containing wastewater. Environ. Sci. 2007;09:2009-2013.

19. Ding J, Shu X, Zhao QL. Influence factors on the treatment of ammonia nitrogen wastewater by electrochemical oxidation. J. Zhejiang Univ. - Eng. Sci. 2013;47(05):889-894.

20. Feng C, Sueiura N, Shimada S, et al. Development of a high performance electrochemical wastewater treatment system. $J$. Hazard. Mater. 2003;B(103):65-78.

21. Kim KW, Kim YJ, Kim IT, et al. Electrochemical conversion characteristics of ammonia to nitrogen J. Water Res. 2006;40(7):1431-1441.

22. Chu YY, Yang B, Li LL, Mou YY, Wang X, Wang SS. Electrochemical oxidation of ammonia nitrogen in two electrolyte systems. J. Chem. Eng. Univ. 2010;24(01):71-75.

23. Mu T, Guo XC, Sun CS. Study on removal of ammonia nitrogen from waste water by three dimensional electrode method. $J$. Northwest A\&F Univ. - Nat. Sci. Ed. 2016;44(11):104-110.

24. Martínez-Huitle CA, Brillas E. Decontamination of wastewaters containing synthetic organic dyes by electrochemical methods: A general review. Appl. Catal. B-Environ. 2009;87(3-4):105-145. 